\title{
The Prevalence of HCV Infection in Hemodialysis Population and Compared ELISA and PCR Methods for Detecting of HCV Infection
}

\author{
Atieh Makhlough, ${ }^{1}$ Mohammadreza Mahdavi, ${ }^{2}$ Iradj Maleki, ${ }^{1}$ Lotfollah Davoodi, ${ }^{3}$ Tahoora Mousavi, ${ }^{4}$ \\ Seyed-Hosein Hasani-Mansoor, ${ }^{5}$ Marjan Makhlough, ${ }^{6}$ and Mohammadreza Haghshenas ${ }^{7,}$ \\ ${ }^{1}$ Gut and liver research center, Mazandaran University of Medical Sciences, Sari, IR Iran \\ ${ }^{2}$ Thalassemia Research Center, Mazandaran University of Medical Sciences, Sari, Iran \\ ${ }^{3}$ Infectious Disease Specialists, Antimicrobial Resistance Research Center, Mazandaran University of Medical Sciences, Sari, IR Iran \\ ${ }^{4} \mathrm{PhD}$ Candidate in Molecular and Cell Biology, Molecular and Cell Biology Research Center, Student Research Committee, Mazandaran University of Medical Sciences, Sari, IR \\ Iran \\ ${ }^{5}$ Research Committee Center, Faculty of Medical Sciences, Mazandaran University of Medical Sciences, Sari, Iran \\ ${ }^{6}$ Institute of Experimental Animal Research, Mazandaran University of Medical Sciences, Sari, Iran \\ ${ }^{7}$ Molecular and Cell Biology Research Center, Mazandaran University of Medical Sciences, Sari, Iran \\ "Corresponding author: Mohammadreza Haghshenas, Associate Professor, Department of Virology, Faculty of Medicine, Mazandaran University of Medical Sciences, Sari, IR \\ Iran. E-mail: haghshenas2001@yahoo.com
}

Received 2017 January 03; Accepted 2017 January 21.

\begin{abstract}
Background: Hemodialysis is one of the renal replacement therapies in patients with end-stage renal failure. The current study aimed at identifying the prevalence of hepatitis $\mathrm{C}$ virus (HCV) infection in hemodialysis population, and comparing serological (enzyme-linked immunosorbent assay) and molecular (polymerase chain reaction) methods to detect HCV infection in North of Iran.

Methods: Serum samples from 162 patients undergoing chronic hemodialysis were collected in 2 hemodialysis units of Sari city (North of Iran). HCV RNAs were isolated from samples using RIBO-prep nucleic acid extraction kit (AmpliSens®, Russia). Total RNAs were extracted from samples and real-time polymerase chain reaction (PCR) was performed using HCV-FRT PCR kit (AmpliSense, Russia) according to the manufacturer's instructions.

Results: In the study, 7 (4.3\%) cases were HCV-Ab positive and 155 (95.7\%) HCV-Ab negative. Additionally, 11 patients (6.8\%) were HCVPCR positive, while 151 (93.2\%) were HCV-PCR negative. Among 11 HCV-PCR positive patients, 7 (63.6\%) were HCV-Ab positive and 4 (36.4\%) were HCV-ab negative. HCV-ab test was not positive in any of the HCV-PCR negative patients.

Conclusions: The results showed that the specificity of HCV-RNA detection was significantly higher than that of the conventional HCV-ab test. The gold standard test to confirm HCV positive should be PCR method.
\end{abstract}

Keywords: Hemodialysis, HCV-ab Test, HCV-PCR Test

\section{Background}

Hemodialysis is one of the renal replacement therapies in patients with end-stage renal failure. Hemodialysis is the 5 th most common procedure for patients aged 45 - 64 years $(1,2)$. Due to the fact that the procedure of hemodialysis requires prolonged vascular access, patients undergoing chronic hemodialysis are at increased risk of blood-transmitted infections (3). The risk of infection is related to several factors including environmental factors such as contaminated devices, equipment and supplies, environmental surfaces, and personnel's hands $(4,5)$, as well as patient related factors such as the number of years spent on dialysis therapy (dialytic age), partial immunosuppressant, regular hospitalizations, and parenteral interventions frequency (6-8).

Hepatitis $\mathrm{C}$ virus (HCV) infection is a serious public health problem (9) and the most significant cause of liver disease in patient receiving dialysis for a long term (10). HCV still remains frequent in patients undergoing maintenance hemodialysis and causes substantial morbidity and mortality in them $(11,12)$. The world health organization (WHO) estimates the universal prevalence of HCV infection around $3 \%(13,14)$. Since the prevalence of HCV in patients undergoing hemodialysis is considerably higher than in general population, it is a permanent concern for hemodialysis units $(15,16)$. Frequency of blood transfusions and HCV prevalence in the blood units, as well as $\mathrm{HCV}$ prevalence in the patients undergoing hemodialysis simultaneously in the same environment are associated with an increased risk for nosocomial transmission of HCV infections (17). An early and accurate diagnosis of HCV in patients with end-stage renal disease should be performed to control the HCV transmission in hemodialysis units (18, 19). 
Patients with chronic renal diseases undergoing hemodialysis are recommended to be screened for HCV infection (19). Currently, the HCV diagnosis is made by 2 main methods; detection of anti-HCV using enzyme-linked immunosorbent assay (EISA), which determines a present or resolved past infection, and detection of HCV-RNA in serum via PCR method, which indicates an active infection (20-23). Detecting reactive antibody against HCV using ELISA is the commom screening test for HCV infection, but it has limitations. The prolonged window period (up to 18 months) and delayed production of anti-HCV in such patients under immunosuppression result in false negatives (up to 22\%) (23). In addition, several studies reported different results about ELISAs in screening HCV infection. In contrast, HCV RNA does persist in serum and is easily detectable in patients with impaired immune functions such as the ones underwent chronic hemodialysis within the first 2 weeks of infection (24).

The current study aimed at evaluating the prevalence of HCV infection in a hemodialysis population, and comparing serological (ELISA) and molecular (PCR) methods to detect HCV infection in Sari, Iran (Mazandaran province) from January to July 2015.

\section{Methods}

The current cross sectional study was conducted from January to July 2015; serum samples of 162 patients undergoing chronic hemodialysis were collected in 2 hemodialysis units in Sari, Iran. The local ethical committees approved the study. The demographic data and patient characteristics such as gender and age, in addition to other data including the cause of renal disease, duration of hemodialysis as well as history of blood transfusion, previous kidney transplantation, drug use, liver disease, and hepatitis $B$ virus (HBV) infection were collected in a datasheet. To perform anti-HCV test, HCV-PCR and biochemical enzymes (blood urea nitrogen, creatinine, alanine transaminase, aspartate aminotransferase, and alkaline phosphatase), 10$\mathrm{mL}$ blood samples were collected from all patients, serum and plasma were separated by centrifugation and stored at $-70^{\circ} \mathrm{C}$.

RNA Extraction: RNAs were extracted from plasma samples by RIBO-prep nucleic acid extraction kit (AmpliSens®, Russia). HCV RNA was isolated from samples by the following procedures: A100 $\mu \mathrm{L}$ of prepared samples was added to the tubes with $300 \mu \mathrm{L}$ solution and vortexed thoroughly; then, tubes were centrifuged for 5 seconds to make sure that there were no drops on the cap, and incubated at $65^{\circ} \mathrm{C}$ for 5 minutes. A $400 \mu \mathrm{L}$ of solution was added for precipitation and votrexed; then, centrifuged for 5 minutes at 13,000 revolutions per minute (rpm). Next, the supernatant was carefully removed without disturbing the pellet using a vacuum aspirator and new tips, then washed with $500 \mu \mathrm{L}$ of washing solution 3 and centrifuged at 13,000 rpm. The supernatant was carefully removed and $200 \mu \mathrm{L}$ of washing solution 4 was added to each tube and centrifuged at 13,000 rpm; then, the supernatant was carefully removed. Finally, all tubes were incubated with open caps for 5 minutes, dried at $65^{\circ} \mathrm{C}$, and $50 \mu \mathrm{L}$ of sterile distilled water was added into each tube, and vortexed. Tubes were incubated at $65^{\circ} \mathrm{C}$ for 5 minutes and centrifuged at $13,000 \mathrm{rpm}$, then RNA quantification was determined using a spectrophotometer and the resulted residue was solved for next stages.

\subsection{Real-Time PCR}

Total RNA was isolated from samples and real time PCR was performed using HCV-FRT PCR Kit (AmpliSense, Russia) according to the manufacturer's instructions. Hepatitis $C$ virus detection from plasma samples along with the internal control sample (IC) was performed under isolation conditions to control the accuracy of results. Briefly, $15 \mu \mathrm{L}$ of the master mix was added to the tubes containing $10 \mu \mathrm{L}$ of extracted RNA. AmpliSens $®$ HCV-FRT PCR kit contained hotstart, which greatly reduced the frequency of nonspecifically primed reactions. The hotstart was guaranteed by separation of nucleotides and Taq polymerase by a chemically modified polymerase (TaqF). The latter was activated by heating at $95^{\circ} \mathrm{C}$ for 15 minutes. The IC amplification product was detected in the FAM channel. The HCV cDNA amplification product was detected in the JOE/HEX channel. The positive control of extraction, positive control-1-HCV, was detected in FAM (IC) and JOE/HEX (HCV) channels. The positive control of amplification, PIC2 HCV (C+), was a complex control for HCV and IC. It is detected in FAM (IC) and JOE/HEX (HCV) channels. The PCR program is presented in Table 1 . PCR reaction was performed using a Rotor Gene 6,000 real-time PCR Machine (Corbett Research, Australia). After this stage, using a computer program, results were immediately determined in programming RT-PCR; besides, positively of test, amount and quantity of virus was determined.

\subsection{Anti-HCVTest}

Anti-HCV was tested using $500 \mu \mathrm{L}$ serum sample, HCV antibody ELISA kit (DSL, Webster, TX, USA) and fully automated ELISA plate reader (Dynex, USA).

\subsection{Biochemical Assessments}

Venous blood samples were collected and serum was separated by centrifugation. The serum value of blood 
Table 1. The Real-Time PCR Program for HCV RNA Detection

\begin{tabular}{|c|c|c|c|c|}
\hline Step & Temperature, ${ }^{\circ} \mathrm{C}$ & Time & Fluorescence Detection & No. of Cycles \\
\hline $\mathbf{1}$ & 50 & $15 \mathrm{~min}$ & - & 1 \\
\hline 2 & 95 & $15 \mathrm{~min}$ & - & 1 \\
\hline \multirow{3}{*}{3} & 95 & $5 \mathrm{~s}$ & - & \multirow{3}{*}{5} \\
\hline & 60 & $20 \mathrm{~s}$ & - & \\
\hline & 72 & $15 \mathrm{~s}$ & - & \\
\hline \multirow{3}{*}{4} & 95 & $5 \mathrm{~s}$ & - & \multirow{3}{*}{40} \\
\hline & 60 & $20 \mathrm{~s}$ & FAM and JOE & \\
\hline & 72 & $15 \mathrm{~s}$ & - & \\
\hline
\end{tabular}

urea nitrogen (BUN), creatinine ( $\mathrm{Cr}$ ) and liver enzymes (aspartate aminotransferase [AST], alanine transaminase [ALT] and alkaline phosphatase [ALP]) were measured enzymatically (Pars Azemoon co.) using Auto Analyzer HITACHI 902.

\section{Results}

A total of 162 patients with the end-stage renal failure undergoing chronic hemodialysis, with the mean \pm SD age of $68.81 \pm 13.76$ years (range, 30 to 94 ) were included in the current study; in which $98(60.5 \%)$ patients were male and 64 (39.5\%) female. The average length of time spent on dialysis therapy was $35.67 \pm 29.99$ (mean \pm SD) months (Table 2). Among them, 117 (72.2\%) patients underwent hemodialysis 3 times a week, 38 (23.5\%) twice a week, and 7 (4.3\%) once a week; 69 (42.6\%) patients had blood transfusion history and 93 (57.4\%) did not (Table 2). Transfusion frequency is presented in Table 3. Moreover, 6 patients (3.7\%) had kidney transplantation previously.

Table 2. Demographic Data and Characteristics ${ }^{\mathrm{a}}$

\begin{tabular}{|lc|}
\hline Characteristics & Data \\
\hline Age, $\mathbf{y}$ & $68.81 \pm 13.76$ \\
\hline \multicolumn{1}{|c|}{ Range } & $30-94$ \\
\hline Gender, male/female & $98 / 64(60.5 / 39.5)$ \\
\hline Duration of hemodialysis, months & $35.67 \pm 29.99$ \\
\hline History of transfusion & $69(42.6)$ \\
\hline History of renal transplant & $6(3.7)$ \\
\hline History of hepatitis B infection & $3(1.9)$ \\
\hline HBS Ag positivity & $5(3.1)$ \\
\hline
\end{tabular}

${ }^{\mathrm{a}}$ Values are expressed as mean \pm SD or No. (\%).
Table 3. Blood Transfusion Frequency in Patients Undergoing Hemodialysis ${ }^{\mathrm{a}}$

\begin{tabular}{lc}
\hline No. of Transfusion & Patients \\
\hline Without transfusion & $93(57.4)$ \\
\hline $\mathbf{1}$ & $22(13.6)$ \\
\hline $\mathbf{3}$ & $24(14.8)$ \\
\hline $\mathbf{4}$ & $13(8)$ \\
\hline $\mathbf{5}$ & $5(3.1)$ \\
\hline $\mathbf{6}$ & $2(1.2)$ \\
\hline $\mathbf{1 1}$ & $1(0.6)$ \\
\hline Undefined & $1(0.6)$ \\
\hline Total & $1(0.6)$ \\
\hline
\end{tabular}

${ }^{\mathrm{a}}$ Values are expressed as No. (\%).

Interviews revealed that 3 patients (1.9\%) had the history of HBV infection. However, none of the patients had the familial history of hepatitis. HBs Ag assessments illustrated that 5 patients (3.1\%) were HBS-Ag positive.

Of all the patients, 7 (4.3\%) were HCV-ab positive and 155 (95.7\%) were HCV-ab negative. Additionally, 11 patients (6.8\%) were HCV-PCR positive, while 151 (93.2\%) were HCVPCR negative. Among 11 HCV-PCR positive patients, 7 (63.6\%) were HCV-ab positive and 4 (36.4\%) were HCV-ab negative. Furthermore, HCV-ab test was not positive in any of the HCV-PCR negative patients. Comparison between the results of the 2 methods (HCV-an and HCV real-time PCR) is presented in Table 4.

Among HCV-PCR positive patients, 7 (63.6\%) were male and $4(36.4 \%)$ female. In other words, $7.1 \%$ and $6.2 \%$ were HCV-PCR positive among males and females, respectively, but the difference was statistically insignificant $(\mathrm{P}=0.825)$.

None of the patients with the history of kidney transplantation showed HCV-PCR positivity. In contrast, 7.1\% 
Table 4. Comparison Between HCV-Antibody and HCV Real-Time PCR Results ${ }^{\mathrm{a}}$

\begin{tabular}{|c|c|c|c|c|}
\hline & & \multicolumn{3}{|c|}{ HCV-PCR } \\
\hline & & Positive & Negative & Total \\
\hline \multicolumn{5}{|c|}{ HCV-ab } \\
\hline & Positive & $7(63.6)$ & 0 & $7(4.3)$ \\
\hline & Negative & $4(36.4)$ & $151(100)$ & $155(95.7)$ \\
\hline Total & & $11(100)$ & $151(100)$ & $162(100)$ \\
\hline
\end{tabular}

${ }^{\mathrm{a}}$ Values are expressed as No. (\%).

of the patients with no history of kidney transplantation were HCV-PCR negative. However, the difference between the 2 groups was statistically insignificant $(\mathrm{P}=0.500)$.

Among HCV-PCR positive patients, 5 (45.5\%) had the history of blood transfusion. In other words, among patients who received previous transfusion $7 \%$ and among the ones with no transfusion history 6.6\% were HCV-PCR positive. The difference was statistically insignificant $(\mathrm{P}=0.910)$.

Interviews revealed that $3(1.9 \%)$ patients had the history of HBV infection and none of the patients had the familial history of hepatitis. HBs Ag assessments illustrated that 5 (3.1\%) patients were HBs Ag positive. None of HCV-PCR positive patients had HBV infection history. Among HBs Ag negative patients, $6.9 \%$ were HCV-PCR positive. The difference between the 2 groups was insignificant $(P=0.637)$.

Duration of hemodialysis in HCV-PCR positive patients was $65.55 \pm 55.10$ months and in HCV-PCR negative cases was $33.49 \pm 26.42$; there was a significant difference between HCV-PCR positive and negative patients ( $P$ $=0.001$ ). Furthermore, HCV-PCR positive cases underwent hemodialysis $2.82 \pm 0.41$ hours per week and HCV-PCR negative patients underwent hemodialysis $2.67 \pm 0.56$ hours per week; the difference was statistically insignificant $(\mathrm{P}=$ 0.387 ) (Figures 1 and 2).

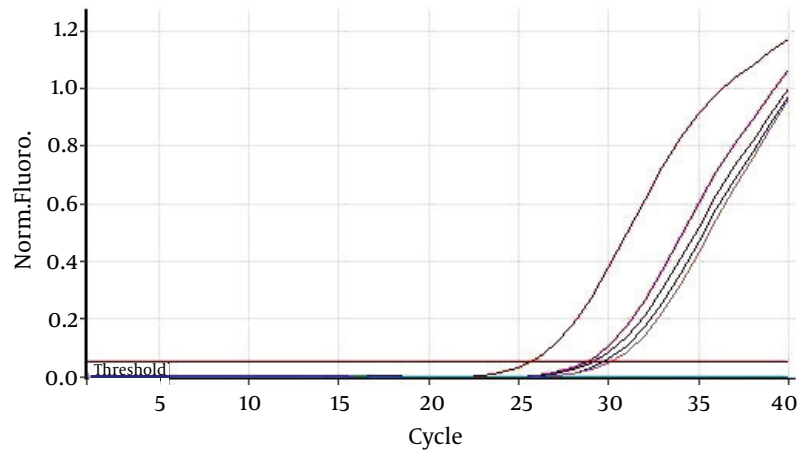

Figure 1. Results of HEX Channel to Detect HCV RNA

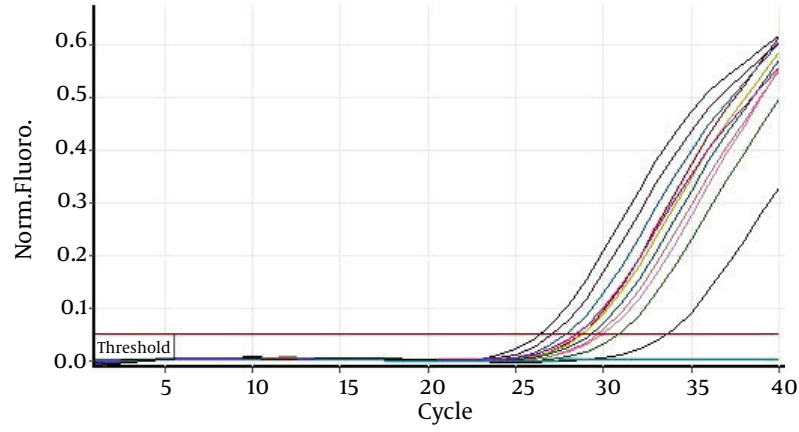

Figure 2. Results of JOE Channel to Detect Internal Control

Biochemical parameters are represented in Table 5. AST values were significantly different between 2 groups $(\mathrm{P}=$ 0.128). Although the values of Cr, ALT and ALP were higher in HCV-PCR positive cases, the difference was statistically insignificant $(\mathrm{P}>0.05)$.

\section{Discussion}

Since the prevalence of HCV in patients undergoing hemodialysis is considerably higher than in general population (25), chronic renal patients undergoing hemodialysis are recommended to be screened for HCV infection (19). Anti-HCV tests are common screening methods used for HCV infection, but they may not accurately reflect true HCV status (26). Despite the advantages of tests in antibody detection such as easy application, relatively low cost, and enhanced sensitivity of recent generations, they still have limitations. The window period between acute infection and antibody production may be more prolonged in such patients with immunodepression $(27,28)$. Due to the slow or delayed seroconversion in the immunodeficiency state; an interval of up to 18 months is reported in patients undergoing hemodialysis (29). Furthermore, another weakness of anti-HCV tests is their incapability to differentiate the present active infection from the recovered past infection (30). In contrast, direct viral detection such as HCV-PCR testing is an effective method; since HCV RNA is detectable in serum within 2 weeks of infection; it vanishes if the infection recovers and persists in chronic infections $(31,32)$. Therefore, HCV-PCR testing can distinguish recovered past infections from present active infections and detect HCV RNA before preseroconversion and antibody production $(33,34)$. Accordingly, PCR method is recommended in addition to HCV antibody testing in this population (35). HCVPCR testing has its own limitations for mass screening, including the cost and high technical skill requirements (36). 
Table 5. Biochemical Parameters in HCV-PCR Positive and Negative Patients

\begin{tabular}{|c|c|c|c|c|}
\hline Biochemical Parameters & HCV-PCR Positive & HCV-PCR Negative & Total & PValue \\
\hline BUN & $83.18 \pm 47.59$ & $97.96 \pm 50.32$ & $96.93 \pm 50.13$ & 0.342 \\
\hline $\mathbf{C r}$ & $8.09 \pm 2.09$ & $6.99 \pm 2.89$ & $7.06 \pm 2.85$ & 0.128 \\
\hline AST & $43.45 \pm 84.01$ & $16.51 \pm 8.83$ & $18.47 \pm 24.33$ & $<0.001$ \\
\hline ALT & $19.90 \pm 16.46$ & $15.24 \pm 11.20$ & $15.55 \pm 11.61$ & 0.400 \\
\hline ALP & $416 \pm 348.88$ & $341.80 \pm 278.62$ & $347.47 \pm 283.83$ & 0.506 \\
\hline
\end{tabular}

HCV-ab was positive in $4.3 \%$ of cases, but HCV-RNA using PCR was positive in $6.8 \%$. The current study results showed lower HCV prevalence than other studies such as those of Caramelo et al. (37), Jadoul et al. (38), makhlough et al. (22), and Moini et al. (36). The decreased prevalence of HCV in the current study in comparison to other studies may be due to multiple factors including HCV screening of blood units, erythropoietin prescription to treat anemia in patients undergoing hemodialysis, using dedicated hemodialysis machine, hygiene improvement in hemodialysis units such as dialysis of HCV positive patients in separate wards, and HCV knowledge improvement in medical professionals.

In the present study, all HCV-ab positive samples showed HCV RNA positivity using PCR method; thus, no false positive result was observed in HCV-ab test; however, $36.4 \%$ false negative results were observed. Therefore, in comparison with HCV-PCR, HCV-ab test has the sensitivity of $63.6 \%$ and specificity of $100 \%$. According to the current study statistical analysis, the specificity of HCV-PCR test was significantly higher than that of HCV-ab test $(\mathrm{P}<$ $0.0001)$. The current study results were in accordance with those of Caramelo et al. (37). Hence, in patients undergoing hemodialysis with no detectable amounts of HCV antibody in their circulation, HCV-PCR is recommended.

In the current study, hemodialysis period was significantly longer in HCV positive than HCV negative patients. The findings were in agreement with those of Makhlough et al. (22) and Duong et al. (39). It seems that the risk of $\mathrm{HCV}$ infection is increased with the increase of hemodialysis period; therefore, these patients require more serious cautions.

The current study findings showed that HCV prevalence was insignificantly different in patients with blood transfusion or kidney transplantation history and patients without such history. It was in contrast with the findings of Duong et al. (39) and Tu et al. (40). At present, nosocomial transmission within the dialysis centers is the main cause of HCV transmission.

In the present study, $1.9 \%$ of cases had the history of HBV infection and 3.1\% were HBs Ag positive; and none of HCV-PCR positive patients had HBV infection history. The current study results were in contrast with those of Tu et al. (40), which demonstrated significant relationship between HCV and HBV infection in patients undergoing hemodialysis. The increasing use of HBV vaccine and screening the blood units result in remarked decrease in HBV infection. HCV still remains frequent in patients undergoing maintenance hemodialysis, due to the lack of HBV vaccine.

In the present study, the values of Cr, ALT, and ALP were insignificantly different in HCV positive and negative cases ( $\mathrm{P}>0.05)$; but AST values were significantly different between the 2 groups $(\mathrm{P}=0.128)$. The current study results were in contrast with those of Caramelo et al. (37) and Duong et al. (39), which illustrated that liver enzymes were significantly higher in HCV positive cases. Most of the individuals newly infected with HCV (60\% - 70\%) are asymptomatic (41). Later, HCV infection tends to become a chronic infection in approximately $75 \%$ of cases (42); subsequently, chronic HCV infection leads to progressive liver diseases such as end-stage liver disease, cirrhosis or liver cancer in $15 \%$ - $25 \%$ of patients; but they most often have an indolent coarse. Moreover, liver enzyme values have lower specificity in patients undergoing hemodialysis than normal individuals; and serum values of liver enzymes were not directly correlated with the degree of liver damage and HCV titer $(43,44)$.

\subsection{Conclusions}

The current study findings demonstrated that the specificity of of HCV-RNA detection test was significantly higher than that of conventional HCV-ab test. As patients undergoing hemodialysis did not have detectable antibody in their serum, using PCR method is highly remarkable.

\section{Footnotes}

Conflict of Interest: Authors declared no conflict of interest in the current study. 
Funding/Support: The current study was financially supported by Mazandaran University of Medical Sciences, Sari, Iran.

\section{References}

1. Pfuntner A, Wier LM, Stocks C. Most frequent procedures performed in US hospitals, 2011. ; 2006.

2. Rafiei A, Darzyani AM, Taheri S, Haghshenas MR, Hosseinian A, Makhlough A. Genetic diversity of HCV among various high risk populations (IDAs, thalassemia, hemophilia, HD patients) in Iran. Asian Pac J Trop Med. 2013;6(7):556-60. doi: 10.1016/S1995-7645(13)60096-6. [PubMed: 23768829].

3. Boelaert JR, Daneels RF, Schurgers ML, Matthys EG, Gordts BZ, Van Landuyt HW. Iron overload in haemodialysis patients increases the risk of bacteraemia: a prospective study. Nephrol Dial Transplant. 1990;5(2):130-4. [PubMed: 2113211].

4. Ibrahim IM. TTV As A Risk Factor In Hemodialysis Process. National Cancer Institute; 2010.

5. Kalantar-Zadeh K, Block G, Humphreys MH, Kopple JD. Reverse epidemiology of cardiovascular risk factors in maintenance dialysis patients. Kidney Int. 2003;63(3):793-808. doi: 10.1046/j.15231755.2003.00803.x. [PubMed: 12631061].

6. Loghman-Adham M. Medication noncompliance in patients with chronic disease: issues in dialysis and renal transplantation. Am J Manag Care. 2003;9(2):155-71. [PubMed: 12597603].

7. Rafiei AR, Hosseinikhah Z, Haghshenas MR, Taheri S, Darziani M. Determination hcv genotype in high risk group (hemophilia-talasemicdialysis-iv drug user) in mazandaran province in sari city. ; 2012.

8. Rafiei AR, Haghshenas MR, Darzyani Azizi M, Taheri S, Babamahmoudi F, Makhlough A, et al. Risk Factors for Hepatitis C Virus Among HighRisk Populations (Intravenous Drug Addicts and Patients with Thalassemia, Hemophilia, Hemodialysis) in Mazandaran. J Mazandaran Univ Med Sci. 2011;21(81):32-42.

9. Shepard CW, Finelli L, Alter MJ. Global epidemiology of hepatitis C virus infection. Lancet Infect Dis. 2005;5(9):558-67. doi: 10.1016/S14733099(05)70216-4. [PubMed: 16122679].

10. Fabrizi F, Poordad FF, Martin P. Hepatitis $C$ infection and the patient with end-stage renal disease. Hepatology. 2002;36(1):3-10. doi: 10.1053/jhep.2002.34613. [PubMed: 12085342].

11. Handajani R, Lusida MI, Darmadi S, Adi P, et al. Differential prevalence of hepatitis $C$ virus subtypes in healthy blood donors, patients on maintenance hemodialysis, and patients with hepatocellular carcinoma in Surabaya, Indonesia. J Clin Microbiol. 1996;34(12):2875-80. [PubMed: 8940415].

12. Fabrizi F, Lunghi G, Ganeshan SV, Martin P, Messa P, editors. Reviews: Hepatitis C Virus Infection and the Dialysis Patient. Seminars in dialysis. 2007; Wiley Online Library; pp. 416-22.

13. Sy T, Jamal MM. Epidemiology of hepatitis $\mathrm{C}$ virus (HCV) infection. Int J Med Sci. 2006;3(2):41-6. [PubMed:16614741].

14. Makhlough A, Mohdavi M, Roshan P. Epidemiology and Treatment of Hepatitis $C$ infection in Hemodialysis patients. J Clin Excellence. 2013;1(1):26-43.

15. Mahdavi-Mazdeh M, Zamyadi M, Nafar M. Assessment of management and treatment responses in haemodialysis patients from Tehran province, Iran. Nephrol Dial Transplant. 2008;23(1):288-93. doi: 10.1093/ndt/gfm580. [PubMed:17965435].

16. Kalantar-Zadeh K, Kilpatrick RD, McAllister CJ, Miller LG, Daar ES, Gjertson DW, et al. Hepatitis C virus and death risk in hemodialysis patients. J Am Soc Nephrol. 2007;18(5):1584-93. doi: 10.1681/ASN.2006070736. [PubMed:17429053].

17. Allander T, Medin C, Jacobson SH, Grillner L, Persson MA. Hepatitis $C$ transmission in a hemodialysis unit: molecular evidence for spread of virus among patients not sharing equipment. J Med Virol. 1994;43(4):415-9. [PubMed: 7545963].
18. Thompson ND, Novak RT, Datta D, Cotter S, Arduino MJ, Patel PR, et al. Hepatitis $C$ virus transmission in hemodialysis units: importance of infection control practices and aseptic technique. Infect Control Hosp Epidemiol. 2009;30(9):900-3. doi:10.1086/605472. [PubMed: 19642900].

19. Intramuscular I. Recommendations for prevention and control of hepatitis $\mathrm{C}$ virus (HCV) infection and HCV-related chronic disease. 1998

20. De Crignis E, Re MC, Cimatti L, Zecchi L, Gibellini D. HIV-1 and HCV detection in dried blood spots by SYBR Green multiplex real-time RT-PCR. J Virol Methods. 2010;165(1):51-6. doi: 10.1016/j.jviromet.2009.12.017. [PubMed: 20045028].

21. Fuentes M, Mateo C, Rodriguez A, Casqueiro M, Tercero JC, Riese HH, et al. Detecting minimal traces of DNA using DNA covalently attached to superparamagnetic nanoparticles and direct PCR-ELISA. Biosens Bioelectron. 2006;21(8):1574-80. doi:10.1016/j.bios.2005.07.017. [PubMed: $16129594]$.

22. Makhlough A, Jamshidi M, Mahdavi MR. Hepatitis C prevalence studied by polymerase chain reaction and serological methods in haemodialysis patients in Mazandaran, Iran. Singapore Med J 2008;49(11):921-3. [PubMed: 19037560].

23. Makhloogh A, Mahdavi MR, Haghshenas M, Ghasemian R, Jamshidi M. Hepatitis $C$ prevalence in hemodialysis patients in Mazandaran, Iran: A survey by polymerase chain reaction and serological methods. Res J Biol Sci. 2008;3(4):265-8.

24. Barrera JM, Francis B, Ercilla G, Nelles M, Achord D, Darner J, et al. Improved detection of anti-HCV in post-transfusion hepatitis by a thirdgeneration ELISA. Vox Sang. 1995;68(1):15-8. [PubMed: 7536987].

25. Lavanchy D. Evolving epidemiology of hepatitis C virus. Clin Microbio Infect. 2011;17(2):107-15. doi:10.1111/j.1469-0691.2010.03432.x. [PubMed: 21091831].

26. Gretch DR. Diagnostic tests for hepatitis C. Hepatology. 1997;26(3 Suppl 1):43S-7S. doi: 10.1002/hep.510260708. [PubMed: 9305663].

27. von Lode P. Point-of-care immunotesting: approaching the analytical performance of central laboratory methods. Clin Biochem. 2005;38(7):591-606. doi: 10.1016/j.clinbiochem.2005.03.008. [PubMed: 16009140].

28. Myers FB, Lee LP. Innovations in optical microfluidic technologies for point-of-care diagnostics. Lab Chip. 2008;8(12):2015-31. doi 10.1039/b812343h. [PubMed: 19023464].

29. Block GA, Raggi P, Bellasi A, Kooienga L, Spiegel DM. Mortality effect of coronary calcification and phosphate binder choice in incident hemodialysis patients. Kidney Int. 2007;71(5):438-41. doi: 10.1038/sj.ki.5002059. [PubMed: 17200680].

30. Erensoy S. Diagnosis of hepatitis $\mathrm{C}$ virus (HCV) infection and laboratory monitoring of its therapy.J Clin Virol. 2001;21(3):271-81. [PubMed 11397664].

31. Krajden M. Hepatitis C virus diagnosis and testing. Can J Public Health. 2000;91 Suppl 1:S34-9. [PubMed: 11059131] S36-42.

32. Khudyakov YE, Obriadina A. Compositions and methods for simultaneous detection of hcv antigen/antibody. Google Patents; 2014.

33. Odari EO. Evaluation of a "combination" ELISA kit and genotyping performance of Restriction Fragment Length Polymorphism among Hepatitis C Virus infected patients' sera. Medical Virology, JKUAT; 2016.

34. Maraqa A, Amr SS, Abdalhamid B. HCV Core Antigen Testing versus HCV PCR Testing for Early Detection of HCV Infection. Egypt J Med Microbiol. 2014;23(2).

35. Alter MJ, Kuhnert WL, Finelli L, Centers for Disease C. Guidelines for laboratory testing and result reporting of antibody to hepatitis $C$ virus. Centers for Disease Control and Prevention. MMWR Recomm Rep. 2003;52(RR-3):1-13. [PubMed: 12585742] quiz CE1-4.

36. Moini M, Ziyaeyan M, Aghaei S, Sagheb MM, Taghavi SA, Moeini M, et al. Hepatitis $C$ virus (HCV) Infection Rate among Seronegative 
Hemodialysis Patients Screened by Two Methods; HCV Core Antigen and Polymerase Chain Reaction. Hepat Mon. 2013;13(6):eeee9147. doi 10.5812/hepatmon.9147. [PubMed: 24032048].

37. Caramelo C, Bartolome J, Albalate M, de Sequera P, Navas S, Bermejillo $\mathrm{T}$, et al. Undiagnosed hepatitis $\mathrm{C}$ virus infection in hemodialysis patients: value of HCV RNA and liver enzyme levels. Kidney Int. 1996;50(6):2027-31. [PubMed: 8943486].

38. Jadoul M, Poignet JL, Geddes C, Locatelli F, Medin C, Krajewska M, et al. The changing epidemiology of hepatitis $C$ virus (HCV) infection in haemodialysis: European multicentre study. Nephrol Dial Transplant 2004;19(4):904-9. doi: 10.1093/ndt/gfh012. [PubMed: 15031348].

39. Duong CM, Olszyna DP, McLaws ML. Hepatitis B and C virus infections among patients with end stage renal disease in a low-resourced hemodialysis center in Vietnam: a cross-sectional study. BMC Public Health. 2015;15:192. doi: 10.1186/s12889-015-1532-9. [PubMed: 25886623]

40. Tu AW, Buxton JA, Whitlock M, Djurdjev O, Chong M, Krajden M, et al. Prevalence and incidence of hepatitis $\mathrm{C}$ virus in hemodialysis patients in British Columbia: Follow-up after a possible breach in hemodialysis machines. Can JInfect Dis Med Microbiol. 2009;20(2):e1923. [PubMed: 20514154].

41. Decker CF. Emerging sexually transmitted diseases: Hepatitis C, lymphogranuloma venereum (LGV), and Mycoplasma genitalium infections. Dis Mon. 2016;62(8):314-8. doi: 10.1016/j.disamonth.2016.03.017. [PubMed: 27109045].

42. Doyle JS, Deterding K, Grebely J, Wedemeyer H, Sacks-Davis R, Spelman $\mathrm{T}$, et al. Response to treatment following recently acquired hepatitis $C$ virus infection in a multicentre collaborative cohort. J Viral Hepat. 2015;22(12):1020-32. doi: 10.1111/jvh.12429. [PubMed: 26098993].

43. Fedele R, Salooja N, Martino M. Recommended screening and preventive evaluation practices of adult candidates for hematopoietic stem cell transplantation. Expert Opin Biol Ther. 2016;16(11):1361-72. doi: 10.1080/14712598.2016.1229773. [PubMed: 27562933].

44. Wedemeyer H, Dore GJ, Ward JW. Estimates on HCV disease burden worldwide - filling the gaps. J Viral Hepat. 2015;22 Suppl 1:1-5. doi: 10.1111/jvh.12371. [PubMed: 25560838]. 